\title{
SPORTS, ENTERTAINMENT, AND THE CLASSICAL WORLD: THEIR USEFULNESS TO MODERN SPORTS POLICY
}

\author{
A Hermann (School of Medicine, The University of Adelaide)
}

\begin{abstract}
Doping has in recent years become a widespread issue throughout the sporting world. Despite the recent plethora of doping cases this is not a new issue, but one which may date to the ancient world including the Classical period. The problems associated with doping must be tackled in a new, more effective manner. This paper assesses positions on sports taken in the ancient world, specifically what was considered cheating or 'doping' — in order to determine if such approaches could be used as a remedy to eliminate / reduce modern doping. The paper will also assess whether such possible solutions could be integrated into anti-doping policy.
\end{abstract}

Keywords: Doping; Athens; Rome; arena

It is well known that doping is a widespread concern in modern day sports, encompassing a large number of participants (Hermann \& Henneberg 2012). Recent scandals such as perpetrated by East Germany (Franke \& Berendonk 1997), the Festina affair (Christiansen 2005), the Chinese swimmers (Jeffery 2008), professional baseball and football in the United States (Mitchell 2007), Lance Armstrong and the US postal team (USADA 2012), Operation Puerto (Cycling News, 2013), and the general doping perpetrated by Russia (WADA 2016), all demonstrate both the widespread issue and the major problems with doping in modern sports. While each new scandal seems to elicit surprise and indignation from officials and the public, it is well documented that this is not a new issue. It has been suggested that doping has been occurring for more than 150 years (Yesalis \& Bahrke 2002; Müller 2010). Moreover, there has been much debate as to whether these practices may have been going on for much longer and whether or not doping was occurring during the Classical period. This is a controversial topic and scholars disagree as to whether the suggested evidence is sufficient to prove the presence of doping in the classical world.

Waddington \& Smith (2009) have suggested that an important indicator of the presence of doping in the classical period can be seen in the ancient Greek Olympics. Before the games, athletes would consume sheep's testicles in order to gain an advantage associated with the testosterone held to be found in the testicles (Lyman 1991). Moreover, gladiators have been shown to follow special diets aimed at improving performance and not only for health reasons (Kanz \& Grossschmidt 2006). 
However, the term 'doping' and its legal consequences did not exist in the ancient world as they do today. Whilst it is true that athletes and sports participants took substances then that, under current anti-doping legislation, may be deemed prohibited (e.g. testosterone), one cannot in retrospect apply modern legislative requirements to historical events. Moreover, many of the doping agents available today were not available in classical times. It can be said that according to today's criteria, 'doping' did not occur in a strictly legal sense. It can be argued, however, that similar intents and similar psychological needs may have existed, which in turn induced the practice forming the foundation of 'doping' today. Given the realities of human nature, the benefits associated with doping during gladiatorial and athletic competitions in the ancient world would have been clear. Pressure on ancient athletes to perform was as on any modern athlete. It is therefore safe to say that even if the practice of 'doping' was not prevalent, cheating was. Moreover, if foods and / or agents were ingested in order to enhance performance, this indicates that the same problems that exist now also existed in the ancient world.

If one can argue that the actions of and motivation for ancient athletes were not dissimilar to the actions / motivation of modern athletes, one could ask why do classical authors / scholars not mention such 'wrongful' practices. Why is doping in modern sports so much more of a problem?

One possible answer is perhaps that these 'scandals' simply did not occur in the ancient world. If this is the case, one may assume the following: 1) that modern society subscribes to significantly lower moral standards than societies from the ancient world (which seems unlikely); and / or 2) that cheating or doping were elements that only just surfaced in the modern world. One response to this can be seen from Higgins (2006) in reference to the doping of horses in the ancient world:

$[\mathrm{C}]$ hariot races and other equestrian sports were an important and highly competitive element of the Games and, as training and fitness targets would have been no less important then, than they are today, it is not unreasonable to assume dietary manipulation and additives were regularly used (Higgins 2006).

Moreover, if the modern world is assumed to have lower moral standards than the ancient world, why would present society even care if cheating or doping occurs? Therefore, perhaps the lack of cheating / doping as an issue in the ancient world is due to the social situation at the time, rather than as a result of changes in human nature. The role sports played in ancient society and, in turn, how athletes were viewed by the public, provides an indication as to what had an impact on these issues. If the primary focus of sports is that of entertainment, then doping 
needs not be an issue. If doping enhanced performance and performance enhanced the entertainment value, then doping was merely a means to a 'legitimate' end agreed on by all concerned. Therefore, if entertainment is the focus of sports, could this eliminate the negativity associated with the issue of doping in sports? If so, a change to the role and view of sports in society may aid in removing the stigma of doping from the modern debate.

This article aims to explore these questions and issues in two ways. First, it seeks to investigate lessons learned from the situation that was prevalent in the ancient world, particularly those that may assist in informing and directing modern sports policy. Second, it attempts to ascertain the extent to which ancient policies and practices could be utilised to help remove the issue of doping in modern sports.

In order to achieve this, this paper discusses the topic in five sections. The first provides a background to the situation. Part two gives a comparative analysis of the similarities between sports in the ancient and modern world from an entertainment perspective. Part three offers an assessment of evidence drawn from the ancient world on issues of cheating or on actions of a doping-like nature. Part four outlines policy implications and recommendations for modern sports. Finally, this paper ends with some concluding reflections.

\section{Why? Background to the situation}

Before the analysis begins, it is prudent to outline the key reasons for the existence of anti-doping policies. This section will also explain why modern policymakers should even care about the concomitant situation in the ancient world.

There are many arguments for the existence of anti-doping policies. The most commonly argued of these include a) fairness, b) health of athletes, and c) the spirit of sports. These justifications for a general anti-doping policy can be found in numerous international conventions, regulations and agreements (WADA 2009) and in publications by some academics (Ritchie 2012).

The first of these, fairness, seems to be quite an obvious and straightforward concept. It is the notion that without anti-doping policies some athletes would act in a manner that creates an imbalance in sport, an inequality between competitors. However, this assumes that sports without doping would be inherently fair and equal. The reality of sports and human nature is very different. The sporting environment, and to a larger extent human society, is and always has been unfair. The phrase 'survival of the fittest' as coined by Spencer (1864), was an objective description of a real situation, not just a felicitous expression of a feeling. The realities of life and sports are such that unfairness exists and is likely always to exist. In a sporting context, disparities can be found everywhere. The most obvious of these are between athletes of differing nations. Athletes from the least developed 
and developing nations are automatically in a position unequal to that of developed nations since they do not have access to the training or the competitions to which athletes from more developed nations have. Even amongst the developed nations, athletes from nations which invest more in sports have an advantage. The lack of access to resources, training, travel, and development programs demonstrates the inequality that results from a lack of funding available for sports. Similarly, various systems and rules in sports create unfairness. Disparities between female and male sporting pay (Kosofsky 1993), segregation of disabled athletes (even if able to compete at the same level as able bodied athletes), age segregation - all demonstrate this inherent unfairness. Some of these elements were present in the ancient world as well.

The second argument in support of anti-doping policies is a concern for the health of athletes. There is considerable evidence to support the idea that some doping agents can indeed cause harm to an athlete if misused (Kohler et. al. 2008). However, many of the substances used in doping, at least originally, had a medicinal purpose. In this way it is not the agents that are harmful, but the abuse of them. This again is a social issue, not a medical one. It can be argued that the abuse of anything can cause human health issues. This includes vitamins and supplements, both of which are allowed in sports. Intensive training techniques likewise can be a problem which can cause considerable negative health effects. Some of the substances banned for health reasons even have little evidence to support the claims (beta-2 agonists are one such example) (Norris, Petersen, \& Jones, 1996; Goubault, Perault, \& Leleu, 2001). In fact there is considerable debate on the inclusion of some agents on the banned list (Korkia 1999). The position in the ancient world was not all that different to that of today. The owners of a gladiatorial school, for instance, would hardly want their fighters to die prematurely, especially given all the time, resources and effort invested in their training. Human health was seen as important, even if associated only with a capital investment, despite the absence of anti-doping policies.

The final argument concerns that of the 'spirit' in which different sports are practiced. Pierre de Coubertin (1894), the founder of the modern Olympics, stated:

L'important dans la vie, ce n'est point le triomphe mais le combat; l'essentiel ce n'est pas d'avoir vaincu mais de s'être bien battu.

The important thing in life is not victory but the battle; the essential thing is not to have triumphed, but to have struggled well.

With this statement, Pierre de Coubertin was able to sum up what the spirit of modern sports should aim for. This was essentially Coubertin's concept of Olympianism. From this philosophy the Olympic Charter (IOC 2015) was 
modelled. Moreover, Coubertin was in many ways inspired by the classical ideals of Olympianism (Ritchie 2014). His vision for the reformation of the Olympics, to mirror that of the classic Greek Olympics, was one that would instil 'a religious sentiment' (Coubertin 1908:580). Honour, knighthood and chivalry (Coubertin, 1894), were key components of Coubertin's vision: 'We must establish the tradition that each competitor shall in his bearing and conduct as a man of honour and a gentleman endeavour to prove in what respect he holds the games and what an honour he feels to participate in them' (Coubertin 1908:546).

It is to further these ideals that the Pierre de Coubertin Medal was established. This medal is awarded for 'true spirit of sportsmanship' and has only been awarded 17 times throughout history. It is clear that the role of the Classical athlete and views of Olympianism were very much at the core of the original modern Olympic movement. The importance of morality, ethics and honour was vital. If the ideal of this moral spirit of the games is one of the primary reasons for anti-doping policy in modern sports, does this mean that ancient athletes lacked morality? Or does this imply that modern athletes' morality is such that, without anti-doping policies, they could not be trusted to remain honest? At present it seems that questions of morality relating to doping are continuously raised. Sometimes this seems as if there is the suggestion that athletes are by their very nature, evil and untrustworthy. Perhaps one of two things should occur. Antidoping prevention programs should be aimed at addressing the issues of ethics and morality or athletes should not be treated like criminals, expected to do wrong. Such changes may encourage people to have a greater respect for the rules.

If action needs to be taken to encourage participants to have more respect for the rules governing a particular sport, rather than focusing on anti-doping, why should modern policymakers even care about the classical position on 'doping'? Even if it may only be a question of:

[t]hose who cannot remember the past are condemned to repeat it - George Santayana (1905:284).

There may still be a lesson to be learned from certain similarities between the sporting situation in the ancient world and that represented by the modern 'games'. Crowther (2007) has demonstrated the striking similarities which exist between modern and ancient sports and practices, which seem to indicate some benefits for the present to be gleaned from perusing the situation in the past.

\section{Sports entertainment then and now}

There are a number of similarities between the modern world of sport and that existing in the ancient world, especially with regard to the entertainment value of 
sport. Sports in the ancient world focused on the sport itself, not on what the athletes ingested in order to participate in such a sport. It may therefore be possible to bring about a change in the role of sports in society, and thereby impact on the doping problem if the focus is purely on the sport and not on the competitor or participant.

One cannot discuss entertainment without addressing the primary role television and sponsorship play in sports in the modern world. Vast sums of money are invested in sports from companies, individuals, or organisations each of which seeks a return on that investment. Many of the world's largest companies invest in marketing and promoting their own products via sport sponsorships. Even companies investing in corporate social responsibility sports programs gain significant reputation, financial and sustainability benefits from these investments (Sheth \& Babiak 2010; Salcines et. al. 2013). The marketing, promotional and profitability benefits of television are well known (Chitty et. al. 2014). If sports on television did not entertain, it would simply not be broadcast. Spectators would need to attend a match or read about it in other media. This demand for entertainment in order to be broadcast creates a vicious cycle as sports needs to entertain to retain viewership without which there are no profits for the investing companies. This adds pressures on managers, coaches and athletes to maintain the level of excitement associated with a sporting event.

In the ancient world, the role of the gladiator was definitely one of providing entertainment. Numerous primary sources demonstrate the emotional state and the excitement levels experienced by spectators and gladiators alike. Reid (2006:37) points out that some athletes today 'actually cultivate their status as entertainers'. This observation is particularly true in the case of modern professional wrestlers. The primary focus of professional wrestling is that of entertainment. There is no attempt to hide this facet of the sport. Many professional wrestling bodies use the value of entertainment as a means of promotional marketing. Examples can be seen in the fact that the world's largest, most renowned, and profitable wrestling entity, World Wrestling Entertainment (WWE), even has the term in their company name. WWE uses promotional phrases such as, Sports-entertainment's greatest good guys (WWE 2014), and The scariest superstars in sports-entertainment history (WWE 2014), as marketing tools. Modern sports are as focused on entertainment as their counterparts from the ancient world.

Another element of comparison between modern and classical sports can be seen with regard to the athletes who participate. Hero worship of both the modern athlete and their gladiatorial counterpart is equally in evidence. There are numerous instances depicting the hero worship of famous gladiators (Hopkins 1983). It has been well documented (Hopkins 1983) that one of the primary 
benefits of gladiatorial 'careers' was that of hero worship. Modern athletes are also often the focus of much hero worship (Holt 1996; Wann et. al. 2001; WADA 2012). Modern athletes such as Hermann Maier, Cristiano Ronaldo, Michael Schumacher, Wayne Gretzky, Alejandro Valverde, Michael Jordan all demonstrate that this phenomenon continues to this day.

The difficulty of building and maintaining a career is further evidence of the similarities between athletes then and now. Poliakoff suggests that gladiatorial games should not even be classified as a sport because:

a gladiator fighting to kill or disable his opponent and save himself in any manner possible is not participating in a sport but in a form of warfare for spectators (Poliakoff 1987:108).

However, modern sports can be said to have at least slight similarity to this aspect. A modern athlete must fight for his / her sporting survival. Current sporting culture has been vamped up to such a level that anything less than a win is often deemed as unacceptable (UNESCO 2006). The result of failure for an athlete may be sporting 'death'. This is evident with the sheer number of relatively successful athletes who, despite great promise, fail to secure their jobs because that one big win eludes them. This is not only because of the importance of the demand for entertainment in sports today, but also because competition in the modern world is as ruthless as it ever was in the ancient world.

Moreover, as pointed out by Potter (1999), in the gladiatorial games, it was not a requirement that one of the gladiators died. Particularly in the latter years of the empire where the games were seen as costly, death was undesirable. In fact, in the latter years of the Roman Empire, the games were considered so expensive that special cost cutting measures were introduced to combat the escalating costs. Measures such as death as a final outcome of a competition were only implemented by imperial decree (Carter 2003). It could equally be argued that these steps were aimed at prolonging a competitor's life in order that the spectacle of the games could be continued. The more famous a gladiator became and the more victories he achieved, the more money the trainer, the 'owner' and the games' organiser would earn. Money was as important then as it is now. The focus on profit is supported by Møller who argues that doping is not due to the need for profit, but that profit itself is the focus:

We can cast aside the thought that the use of doping is a perversion that has become prevalent due to the dizzying sums of money that have flowed into sports (Møller 2009:32).

As with the gladiator who was judged to be important if he generated profit for his 'team', measures were taken in Formula 1 to improve the entertainment value of 
racing. During the late 1990's and early 2000's, Michael Schumacher was enjoying an almost incomparable run of success. At the time, this was deemed to be 'boring' by a number of organisers and some spectators. In an attempt to 'combat' these results, changes were introduced to end his dominance and make the sport more 'entertaining' and as such again, more profitable. It can be argued that this action was in direct conflict with the spirit of sports and the spirit of fairness. Similar changes have been introduced in the Dakar Rally event. Changes were made to the motorbike categories (Amaury Sport Organisation 2011) in an attempt to end the dominance of KTM. A less cynical view of this action is that it was done for reasons of entertainment, again neglecting the values of a) performance of the best athlete and b) the spirit of sports and fairness.

The vision of Coubertin for modern sports was one of 'brotherhood' and unity; the idea that there was a spirit of sportsmanship amongst fellow competitors. However, one can say this vision has changed dramatically, particularly since the professionalisation of sports. In modern sports, there are a number of athletes, managers, and coaches who consider victory the only acceptable outcome to an event (Foot 2007; Coyle \& Hamilton 2012; Anderson 2016). This unfortunately may be one of the driving forces behind the doping epidemic sports now endure.

In the ancient world evidence of the importance of being the best and victory at any cost can be seen in the fact that only one prize was awarded. The laurel wreath, the prize for victory, was only awarded to those who won. There were no prizes for the remaining places. Pindar tells of the indignity of defeat (Pythian 8.85), and of young athletes hiding in shame. The importance athletes placed on winning in the ancient games was not unlike the modern obsession with victory. The main difference was that the honour of victory also extended very directly to the city / country of origin of the victor.

Another point of similarity between participating as an athlete in the ancient world and the modern is the presence of the summa rudis at the competition. This official could be considered the classical equivalent of a referee in boxing or mixed martial arts. Carter (2003) defines this person as a 'technical expert'. The role of the summa rudis was to stop combat before a death occurred, whilst still maintaining the entertainment value of the spectacle. He could even stop the fight before a gladiator surrendered, again similar to a modern referee. This was so to preserve the life of the athlete, so that they could continue to fight / compete again in future, thus ensuring the continuance of the athlete's value and his contribution to the spectacle. Given the power of a summa rudis it is also possible for influence to be exerted on this official. One such example is found in Diodoros from Amisus' epitaph of a gladiator in Asia Minor, where it states 'the cunning treachery of the summa rudis' as the reason for his death (Robert 1940). Whilst this may simply be an unhappy friend looking for someone to blame for 
this death, it can also be seen as a potential avenue for the classical 'athlete' to gain unfair advantage over a competitor. These issues of corruption of referees still exist in modern sports. Recent issues with World Cup host city voting are one such example (Lawton 2011). The existence of corruption in the ancient world seems to suggest that cheating / 'doping' in some form may also have existed.

The importance of the spectacle (and victory) saw that other questionable decisions were taking place in the ancient world. Remijsen (2009:247) notes that the ruler of Syracuse, Gelon, had 'paid the best sprinter of the moment to compete for Syracuse instead of his home town'. This is but one example of this practice; there are numerous other examples of performance buying in classical literature (i.e. Pausanias' Description of Greece 6.13.1; Pindar Pythian 1).

This act of buying the best athlete could be seen as an attempt to enhance the spectacle. Gelon would have no doubt used the sprinter to win the favour of the crowd. A happy crowd, because of an entertaining event with a positive outcome for the 'home team', would no doubt be more supporting of his rule. This event again demonstrates the similarity with modern sports and the importance of the effect associated with spectacle. No one disputes the ongoing debates about questionable decisions in modern sports (be it referees or corrupt officials). Questionable decisions are sometime just human mistakes, but more often than not there is some benefit associated with taking an incorrect decision just as some benefit was associated (or anticipated) by Gelon in buying a 'foreign' sprinter to compete for Syracuse.

The same aspect (buying a better athlete to enhance one's chances of victory) can be seen with the 'transfer of allegiance' allowance (IAAF 2013) in modern athletics. This 'allowance' permits the transfer of nationalities of athletes. These athletes even if they once may have competed for their home nation, are able to later compete for a foreign nation. They do not have to acquire citizenship in the regular manner and then compete for their adopted nation. They are simply granted an express citizenship and then transferred. Once again this indicates that modern sports and classical spectacles are not all that dissimilar.

The consequences and public responses relating to the two examples outlined above (Gelon of Syracuse and Diodoros of Amisus) can be used as a means to measure the classical views on such occurrences. In both cases there would no doubt have been a general feeling of frustration aimed at the organisers (at least from the town that the sprinter abandoned). However, in the eyes of the newly adopted town (the winning town) the public view would have been that the spectacle (and the fact that they had won) was more important than the details (with a 'bought' athlete). Much like today's spectator standards, it would seem that not too many spectators have an issue with an athlete from a foreign nation changing nationalities. This is particularly true in cases where their nation is 
benefiting from the transfer of allegiance (this would of course depend on the sport, its role in that culture / nation, and the individual in question). Yet the question remains undecided. Is the spectacle more important than the spirit of the game, or is it just the perception of modern spectators?

There are also features relating to the structuring of modern sports, in which one can view similarities between then and now. Carter (2006) outlines the gladiatorial ranking system policies in place in 177 AD (Senatus Consultum De Pretiis Gladiatorum Minuendis). This legislation placed caps on gladiators' payments and base their skills' values based on their munus category. The munera could be classified into one of four categories according to the overall costs associated with its payment.

One possible explanation of the introduction of these levels was in order to inform the spectators more fully as to what to expect from the event; so that the spectators were not less entertained or disappointed due to high expectations and low outcomes. Again this shows that the gladiatorial games and their participants were not altogether different from modern athletes and sports. Numerous sports have in place ranking systems which either directly or indirectly impact of the athletes' value. Moreover, such ranks in turn impact on participation at events, which events will contain which athletes, and indirectly the entertainment value of the event. Some sports, such as Rugby League (NRL) in Australia, adopt a similar approach and place salary caps on clubs (NRL 2013). It is said that salary caps make the contest more fair and equal, but perhaps again the entertainment value is not altogether forgotten. Teams that are more 'equally' matched will make for a more entertaining show. The argument is that without the cap, some teams would be undesirable to play for because of lack of money. As a result there would be the skewing of outcomes towards the wealthiest teams. These teams would prove to be too powerful, would be always winning, and thus diminish the spectacle.

Finally, one key indicator of the similarity between sports then and now can be seen in the comments by some sports commentators. It has been suggested by some that sports are first and foremost an entertainment medium (Keenan 2011). Similarly, it has been suggested by Lumer (1995:8) that:

There is an ... agreement between them that the players do their best in striving for victory, thereby usually giving an exciting competition, and that the spectators pay for this by money ...

In short sports now as then are still seen as entertainment. If so, the doping problem lies not in the fact that sports are designed to be entertaining, but that there is a conflict between this expectation of entertainment and the expectation of fairness, uninfluenced by outcomes. 


\subsection{Athletes' health — then and now}

The works by Kanz \& Grossschmidt (2009), Longo et. al. (2008), and Eichholz et.al. (1938) show that ancient athletes placed considerable emphasis upon their health, in addition to performance. Health was important for survival. Survival helped to ensure income from entertainment. If one then compares this to the current situation, devolution has occurred in some ways. Firstly, in reference to the work by Goldman \& Klatz (1992), approximately half of the respondents (modern athletes) stated they were willing to die after five years if they could be guaranteed success. This demonstrates that in the modern sporting world, if the results of entertainment and victory are to be achieved, something must be surrendered in return, in this case life.

Moreover, training in many sports are, by their very nature, harmful to human health. Athletes often report signs of injury and ill health following retirement (Hadhazy 2008; Sundgot-Borgen et.al. 2013). Death is also not all that uncommon as a result of the efforts associated with the career of an athlete. Perhaps it is not doping that should be recognised as causing the greatest harm to athletes' health, but rather sports training and specialisation, or as Plato puts it:

The athlete's nature is drowsy ... and the least variation from his routine is liable to cause him serious illness (Rep. 3. 404A).

\subsection{Athletes' nutrition - then and now}

A key aspect of sporting life in the ancient world can be seen in the diets of ancient Greek athletes and Roman gladiators. It was standard practice in Ancient Greece to use an assortment of natural substances such as herbs and fungi, honey, or caffeine in order to aid athletic performance (Papagelopoulos et. al. 2004). Since this time, modern scientists have demonstrated the various medical and performance enhancing properties of a number of natural substances, either as vitamin supplements or simply as a necessity in the diets of modern athletes. In the same vein the diet of the gladiator benefitted from supplements. A gladiator's diet has been shown to have consisted of oats and barley (Kanz \& Grossschmidt 2009). This diet produces, among other things, a subcutaneous layer of fat. This subcutaneous layer of fat may have been particularly useful should a slash wound be inflicted on a combatant in a gladiatorial battle. This layer of fat acted as a type of barrier against serious harm to the gladiator. There was a reduced chance of damaging muscle, veins and nerves and thus the gladiator could heal quicker and / or continue to fight (Kanz \& Grossschmidt 2009). This helped ensure two things, 1) survival and health of the athlete and 2) as a consequence (and perhaps more importantly to the organisers) the ongoing spectacle of the game. In fact, it has 
been suggested by Kanz \& Grossschmidt (2009), that 'surface wounds look more spectacular' in gladiators who abided by the gladiatorial diet. It was suggested that they may have in fact used the subsequent subcutaneous fat for entertainment purposes (Curry 2008).

Another example can be seen in sports where weight was considered advantageous, such as wrestling and boxing. In these sports a forced diet was introduced (Manning 1917). This was a change from the original dietary practices in these sports. Traditionally, athletes in these sports would have had 'normal' diets including cheese, dried figs, and porridge (Diog. Laert. Lives 8:12). This dietary change can be said to have altered the focus for both the athlete and the spectator.

A diet primarily focused on large quantities of meat (for protein), brought with it changes to the appearance of the athletes, their performance and the spectacle which they could generate. A more muscular and larger athlete would have been appealing as a spectacle for both female and male spectators. Larger, stronger, 'better looking' athletes would have brought with them many more fans, more money, greater spectacle and greater prestige; a fact not lost in modern sports. One additional point to note is that these policies and the subsequent training requirements meant that poorer people were unable to compete (Manning 1917). This again indicates that the entertainment value seemed to outweigh the spirit of the sports, mimicking in some ways the issues of modern sports. Diets and the ingestion of substances were, in classical times, simply not considered a form of cheating. The aforementioned use of sheep's testicles as a form of testosterone ingestion is witness to this. In fact, such practices were encouraged and were part of the gladiatorial training; they were simply a means to an end, the end of entertaining crowds.

\subsection{Sports culture - then and now}

Given this focus on entertainment, why then are similar practices and agents in modern sports such an issue today? Whilst it is true that that the method of delivery of doping agents differs (for example blood doping) and that many modern substances are artificial vs. natural sources in classical times, the general concept behind the use of these substances remains the same; to enhance performance.

Many of the 'legal' practices of modern athletes aim at performance enhancement, i.e. altitude training, vitamins, supplements ... Why then are certain types of substances now considered taboo? Is entertainment seen as such a base desire, not worthy of a modern society, that all sports need to appear as being in the pursuit of higher ideals? Evidence of this view can be seen from responses and comments relating to professional wrestling. It has often been argued that 
professional wrestling is simply not a sport, that it is scripted, or rather, is nothing more than a distraction without substance and simplistic in nature (Hamdan 2016; McGregor 2016). This seems to imply that if entertainment is the objective, athletic competition cannot exist, that entertainment and competition are mutually exclusive. In the ancient world the ingestion of chemicals, or food supplements were not such an issue, since the focus was in the first place on entertainment.

However, the Greek poet Pindar summed up the real aim of sport in ancient Greek culture as follows:

To present yourself and compete in the stadium of Olympia you must be perfect. What does perfect mean teacher?, asks Filinos the athlete. The body, Filine, is cultivated with exercise, the soul with music and the mind with knowledge. This is the only way to make beauty. In beauty is tightly preserved the idea of man. Man is not only he who has a strong body, but he who has at the same time a beautiful soul and mind. Thus beauty is the expression of this completeness, and this perfection is the virtue. He who has virtue is perfect - Pindar (op. cit. Arvaniti 2006:354).

Pindar's summary indicates that there was more to athletic performance than just winning or just entertaining the spectators. In this regard there is an element of achievement involved in the actions of athletes. This achievement can only arise through one's own dedication and effort. The achievement is not purely physical in nature, but at the same time also incorporates both spiritual and mental endeavours. It is the virtue of the soul and that of completeness that are the true measure of a person. So perhaps doping was not a problem in the classical world because for an athlete to achieve this higher goal, the unity of the three aspects of perfection (a completeness), the person must undergo training in all three aspects, not only physical. To enhance only the physical elements would therefore mean detracting from the spiritual and metal aspects.

Furthermore, the games in ancient Greece were designed as a means of showing respect to the Greek gods (Grandjean 1997). Any practice aimed at intentionally cheating or misleading the sporting world (or any general unethical acts) were viewed as offending the gods. Homer informs his readers of the consequences of offending one of the Greek gods:

Apollo killed the sons with arrows from his silver bow, to punish Niobe, and Diana slew the daughters, because Niobe had vaunted herself against Leto (Homer, Il. 24).

Niobe's pride and her offence towards Leto resulted in the death of her family. Similar consequences can be found with Aglauros' offense to Hermes, who, as a result, turned Aglauros to stone (Ovid, Met. 2.812-832). Finally, the worst of all 
punishments, Tartarus, awaited the greatest sinners, those who had the greatest transgressions against the Greek gods. The greatest sinners would suffer temptation without reprise, unending torment, unfulfilled trials all for offending the gods (Homer, Od. 11.576-600; Ovid, Met.10.40-44). With consequences such as these it is no wonder most ancient Greeks would not want to offend the gods. Moral standards and societal expectations may therefore well have played a big role in the decision not to dope.

Substances that are now considered to be doping agents were ingested in the ancient world to enhance performance. These acts seem to have been tolerated because to do anything else would be to suggest the athletes were disrespecting the gods. Such an idea is something that would not have been readily accepted by the athletes or even their fans. Moreover, and more practically, it would have been impossible to regulate fully the dietary intake of all athletes throughout the ancient world. Consequently, the ancient Greeks may simply have been more realistic about what is today considered as doping.

Similarly, cultural elements played an important role in the careers of gladiators. As outlined previously, it would seem that the primary focus of the gladiatorial combat was entertainment. It has been suggested that such combat was a means for Romans to attempt to exert some level of control over the chaotic world around them (Futrell 1997), but in a managed space. If this is the case, doping would not have been seen as a priority but rather as an aspect of entertainment and another means of taking control of a difficult situation. Furthermore, as can be seen on a number of gladiatorial funeral epitaphs, it was not their opponents that were blamed for gladiators' deaths but rather the Parcae / Moirai (Fates) (Carter 2006). The Fates are said to descend from Zeus and Themis (Titan of Law) and as such embody concepts such as justice and lawfulness like that of their siblings (Hesiod, Theogony, ll. 901-906; Roman \& Roman 2010). This is of particular note, because they are argued as being the cause of numerous gladiators' deaths. Perhaps one can align this concept with that of doping. This could be seen as the enactment of justice, order and lawfulness, on those that committed a transgression; a transgression, which whilst punishable, is not one that warranted the punishment of the gods. This assertion is perhaps justified by the fact that not all gladiatorial epitaphs made mention of the Parcae as being the cause of the gladiator's death. So the question is, can the inclusion of the Parcae on some gladiatorial epitaphs be seen as evidence of the gladiators' 'transgressions' into doping / cheating?

So the Fates would decide on the outcome of combat, but the gladiator still had to take control to the best of his ability to manage the situation itself and entertain the spectators in the process. 


\section{Policy implications and recommendations}

Athletic events in the ancient world seem to be focused on entertainment. Many of the same attributes exist in modern sports as well as the same basic human psychological needs. The key difference between then and now seems to be the role sports have in society, especially the spectators' views on it. Sports then emphasised entertainment. Whilst the individual and his skills were vital to the entertainment factor, this was secondary to spectator's satisfaction. The long term destiny of the participants was in the hands of the Fates.

If like in modern sports the spectators expected more from an event than mere entertainment, if they expected the event to be entertaining, fair, equal, natural, uncontrolled, and without influence, then anything less than this would create issues. However, in order to achieve the modern spectator's utopian view of a spectacular sporting event, it seems that additional realities slip into the modern sporting environment such as doping, corruption or both. These factors in turn contradict the values and desires of the spectators. Given the realities of sports, the realities of human psychology, and the very real expectations of spectators, the problems in the modern sporting environment seem to be caused at least partially by a conflict of expectations.

Therefore, one possible approach to solving the problem of doping in modern sports is to take a leaf from the book from the ancient world and refocus sports' expectations to that of entertainment only. If the spectacle of the sport is the key focus, then steps will need to be taken to ensure this. This is especially true in an inherently chaotic and unpredictable setting. It is, however, unfeasible to expect that sports will fulfill every need and desire of the sporting community in every match. The cynical conclusion will then be that doping is not an issue, if the focus of sport is on entertainment. If the sporting public demands more than that if it also demands fairness), it has to be prepared to accept that there may be a diminished level of spectacle as a result. However, given recent findings (Hermann \& Henneberg, 2012; Hermann \& Henneberg 2014) there may not in fact be any diminishment of the spectacle. Some doping may harm performance and as such the elimination of doping may in fact improve the spectacle.

At present what seems clear is that doping policies may have changed, and the application of societal issues may also have evolved, but the underlying concerns remain. The anti-doping policy is in place to attempt to retain some sort of control over a system of competition which is by its very nature chaotic and unpredictable if left to run its natural course. The general societal unease with lack of control remains. This may also further explain why currently there is such an issue with corruption in a number of sports. There is a general conflict between the psychological need of control over the chaotic, and the need for fairness and 
honesty. As such any attempt to artificially influence the outcomes of a sport may be viewed as being unjust even if the actions are generally intended to aid the sport and the spectacle. It would therefore seem that doping itself is not the problem, but rather it may be seen to some as a solution to the problem that sports need to fulfill a multitude of conflicting expectations. Either way, anti-doping policies may be an attempt to alleviate this concern. If this is the case, modern sports have simply replaced one principle of sports (a focus on entertainment) as a means of control with another (a focus on anti-doping). A refocusing of sport's role to that of entertainment as opposed to fulfilling some sort of higher societal ideal may satisfy both roles.

One possible alternative, whilst more beneficial to society at large, but more difficult to achieve, is to aim for a change in society. Ethical and moral expectations in ancient society may have been acting as a self-governing component to counter large scale corruption and cheating. The importance of respecting the gods, the ridicule associated with cheating may have added to many athletes' desire not to cheat. The modern world could perhaps learn from this and from Coubertin's original ideals of the modern Olympics. The value of honour, chivalry, respect, ethics and morality should be reinforced in society at large. This change in societal values would bring about a reduction in the rates of doping and cheating for a number of reasons. Athletes would not want to dope as it would go against their own values and morals. Moreover, society would not condone doping. Athletes caught out would be so ridiculed that this would act as a deterrent. Overall, a change in societal ethical and moral standards globally (whilst difficult) would aid in the removal of these issues. In addition it would focus the debate on the values held by athletes and spectators alike and not only focus on the transgressions of the participants.

\section{Conclusion}

Overall four points were made in the preceding sections. 1) Modern sports and classical sporting contests are in essence remarkably similar. The similarities are striking; only the names and applications of the same principles have changed. Entertainment was and is the focus then and now even though what constitutes entertainment has changed. 2) Culture and the values of the society perhaps played the biggest role in sports in ancient times. This may have resulted in a self-policing environment. 3) Modern anti-doping policies should not be purely based on legislature, but rather be seen as a reflection of the values of current society which need to be addressed. 4) The term doping perhaps needs to be reassessed, 'sporting immorality' may provide a more accurate image of the psychological and motivational undertones of doping. Anti-doping as a means of control is ineffective 
and as such a refocusing on shared values needs to be made. Moreover, a refocusing of the societal view of sports to one more orientated to that displayed by professional wrestling may well eliminate the issues associated with doping.

Either sport should focus on entertainment and spectators' views on the role of sports should change or society's views on the applicability of ethics and morality in sports need to change. Basically, either sports should be purely entertaining (by any means) or purely competitive (with less focus on entertainment).

In addition, modern spectators may perhaps need to look within themselves to find satisfaction with life and moral fortitude, instead of trying to focus on athletes to supply such satisfaction. ${ }^{1}$

\section{BIBLIOGRAPHY}

Amaury Sport Organisation 2011. Dakar rally: Sporting aspects. Available at: http://www.dakar.com/2011/DAK/presentation/us/r3_2-aspectssportifs.html (accessed $15^{\text {th }}$ July 2013).

Anderson, E 2016. Doping in sports: Winning at any cost? Booklist 1:30.

Arvaniti, N 2006. Ethics in sport: The Greek educational perspective on antidoping, sport in society. Sport in Society 9.2:354-370.

Carter, M 2003. Gladiatorial ranking and the 'SC de Pretiis Gladiatorum Minuendis' (CIL II 6278 = ILS 5163). Phoenix 57.1/2:83-114.

2006. Gladiatorial combat: The rules of engagement. The Classical Journal 102.2:97-114.

Chitty, W, Luck, E, Barker, N, Valos, M, Shimp, T \& Andrews, J 2014. Integrated marketing communications, $4^{\text {th }}$ Asia Pacific Edition, Cengage Learning Australia.

Christiansen, A V 2005. The legacy of Festina: Patterns of drug use in European cycling since 1998. Sport in History 25.3:497-514.

Coubertin, P 1894. Circulaire Annonçant le Congres International Athlétique. January $15^{\text {th }} 1894$. Paris.

1908. Olympism. Fortnightly Review July 1908.

Coyle, D \& Hamilton, T 2012. The secret race: Inside the hidden world of the Tour de France: Doping, cover-ups, and winning at all costs. London: Bantam Books.

Crowther, N 2007. Sport in ancient times. Greenwood Publishing Group Westport. Curry, A 2008. The gladiator diet. Archaeology 61.6:28-30.

Acknowledgement: The author would like to thank Professor Paul Babie for his advice and guidance on this topic. 
Cycling News 2013. Fuentes found guilty in Operacion Puerto trial, April $30^{\text {th }}$ 2013. Available at: http://www.cyclingnews.com/news/fuentes-foundguilty-in-operacion-puerto-trial (accessed $16^{\text {th }}$ July 2013).

Foot, J 2007. Winning at all costs: A scandalous history of Italian soccer. New York: Nation Books.

Franke, W \& Berendonk, B 1997. Hormonal doping and androgenization of athletes: A secret program of the German Democratic Republic government. Clinical Chemistry 43.7:1262-1279.

Futrell, A 1997. Blood in the arena: The spectacle of Roman power. Austin: University of Texas Press.

Goldman, R \& Klatz, R 1992. Death in the locker room: Drugs \& sports (2 ed.). Chicago: Elite Sports Medicine Publications 24.

Goubault, C, Perault, M, Leleu, E, Bouquet, S, Legros, P, \& Vandel, B 2001. Effects of inhaled salbutamol in exercising non-asthmatic athletes. Thorax 56:675-679.

Grandjean A 1997. Diets of elite athletes: Has the discipline of sports nutrition made an impact? The Journal of Nutrition 127.874 S-877S.

Gunderson, E 1996. The ideology of the arena. Classical Antiquity 15.1:113-151.

Hadhazy, A 2008. Concussions exact toll on football players long after they retire. Scientific American September $2^{\text {nd }} 2008$.

Hamdan, L 2016. Let me entertain you: WWE's Gerrit Meier, Arabian Business, May $13^{\text {th }}$ 2016. Available at: http://www.arabianbusiness.com/let-meentertain-you-wwe-s-gerrit-meier-631569.html\#.V_OXJDX044I (accessed on $4^{\text {th }}$ October 2016).

Hermann, A \& Henneberg, M 2012. The doping myth: $100 \mathrm{~m}$ sprint results are not improved by 'doping'. International Journal of Drug Policy 24.2:110-114.

Hermann, A. \& Henneberg, M 2014. Long term effects of doping in sporting records: 1886-2012. Journal of Human Sport \& Exercise, 9.3:727-743.

Higgins, A 2006. From ancient Greece to modern Athens: 3000 years of doping in competition horses. Journal of Veterinary Pharmacology and Therapeutics 29.Suppl.:1-10.

Holt, R 1996. Cricket and Englishness: The batsman as hero. The International Journal of the History of Sport 13.1:48-70.

Hopkins, K 1983. Death and renewal Vol. 2, Sociological studies in Roman history. New York: Cambridge University Press.

International Association of Athletics Federations 2013. Transfer of allegiance. Available at:

http://www.iaaf.org/about-iaaf/documents/transfer-of-allegiance\#athletetransfer-of-allegiance (accessed $16^{\text {th }}$ July 2013). 
International Olympic Committee 2015. Olympic Charter. Available at: https://stillmed.olympic.org/Documents/olympic_charter_en.pdf, accessed on $10^{\text {th }}$ May 2016.

Jeffery, N 2008. Systematic Chinese doping scams exposed. Available at: http://www.theaustralian.com.au/news/chinese-doping-scams-exposed/storye6frg7y6-1111116988254), (accessed 24 ${ }^{\text {th }}$ April 2013).

Kanz, F \& Grossschmidt, K 2006. Stand der anthropologischen Forschungen zum Gladiatorenfriedhof in Ephesos. Jahreshefte des Österreichischen Archäologischen Instituts in Wien, 103-124.

Kanz, F \& Grossschmidt, K 2009. Dying in the arena: The osseous evidence from Ephesian gladiators. In Roman amphitheatres and spectacula, a $21^{\text {st }}$ century perspective: Papers from an international conference held at Chester. British Archaeological Reports Ltd., 16th-18th February, 2007:211.

Keenan, M 2011. SBS Tour de France coverage. Special Broadcasting Service.

Kohler, M, Thevis, M, Schänzer, S, \& Püschel, K, 2008. Gesundheitsschäden und Todesfälle durch Doping. Rechtsmedizin 18:177-182.

Korkia, P 1999. Drugs in sport. Journal of Substance Use 4:125-127.

Kosofsky, S 1993. Toward gender equality in professional sports. Hastings Women's Law Journal 4:209.

Lawton, M 2011. Now FIFA must vote again on 2022 World Cup. Mail Online, $31^{\text {st }}$ May 2011. Available at:

http://www.dailymail.co.uk/sport/football/article-1392570/FIFA-vote-2022World-Cup.html (accessed $16^{\text {th }}$ July 2013).

Longo, U G, Spiezia, F, Maffulli, N, \& Denaro, V 2008. The best athletes in ancient Rome were vegetarian! Journal of Sports Science and Medicine 7:565.

Lumer, C 1995. Rules and moral norms in sports. International Review for the Sociology of Sport 30:263-281.

Lyman, M 1991. Drugs in society: Causes, concepts and control. Burlington: Routledge.

Manning, C 1917. Professionalism in Greek athletics. The Classical Weekly 11.10:74-78.

McGreger, C 2016. Conor McGregor: @TheNotoriousMMA, Twitter, $7^{\text {th }}$ August 2016. Available at:

https://twitter.com/TheNotoriousMMA?ref_src=twsrc\%5Etfw (accessed on $4^{\text {th }}$ October 2016).

Mitchell, G J 2007. Report to the commissioner of baseball of an independent investigation into the illegal use of steroids and other performance enhancing substance by players in major league baseball, Office of the 
Commissioner of Baseball. Available at: http://files.mlb.com/mitchrpt.pdf (accessed June 30 ${ }^{\text {th }}$ 2012).

Møller, V 2009. The ethics of doping and anti-doping: Redeeming the soul of sport? New York: Routledge.

Müller, R 2010. History of doping and doping control. In Doping in sports: Biochemical principles, effects and analysis. 1-23. Heidelberg: Springer.

Neils, J 2014. Picturing victory: Representations of sport in Greek art. In Christesen, P \& Kyle, D, A companion to sport and spectacle in Greek and Roman antiquity. 81-97. Chichester: John Wiley \& Sons.

National Rugby League Australia, (2013), Salary cap. Available at: http://www.iaaf.org/about-iaaf/documents/transfer-of-allegiance\#athletetransfer-of-allegiance (accessed $15^{\text {th }}$ July 2013).

Norris, S, Petersen, S, \& Jones, R (1996). The effect of salbutamol on performance in endurance cyclists. European Journal of Applied Physiology and Occupational Physiology 73:364-368

Papagelopoulos, P, Soucacos, P, Mavrogenis, A 2004. Doping in ancient and modern Olympic Games. Orthopedics 27.12.

Poliakoff, M 1987. Combat sports in the ancient world. New Haven: New Haven Press.

Potter, D 1999. Entertainers in the Roman Empire. In Life, death, and entertainment in the Roman Empire (eds. D S Potter \& D J Mattingly). Ann Arbor: University of Michigan Press.

Remijsen, S 2009. Challenged by Egyptians: Greek sports in the third century B.C. The International Journal of the History of Sport 26.2:246-271.

Reid, H 2006. Was the Roman gladiator an athlete? Journal of the Philosophy of Sport 33.1:37-49.

Ritchie, I 2012. The 'spirit of sport'. Understanding the cultural foundations of Olympism through anti-doping policies. In International Centre for Olympic Studies, problems, possibilities, promising practices: Critical dialogues on the Olympic and Paralympic Games. 80. Eleventh International Symposium for Olympic Research. Ontario,

— 2014. Pierre de Coubertin, doped 'amateurs' and the 'spirit of sport': The role of mythology in Olympic anti-doping policies. The International Journal of the History of Sport 31.8:820-838.

Robert, L 1940. Les gladiateurs dans l'Orient grec. Paris, reprint Amsterdam 1971. Roman, L \& Roman, M 2010. Encyclopedia of Greek and Roman Mythology. New York: Facts on File.

Salcines, J, Babiak, K \& Walters, G 2013. Routledge handbook of sport and corporate social responsibility. London: Taylor \& Francis.

Santayana, G 1905. Reason in common sense. Cambridge: The MIT Press. 
Sheth, H \& Babiak, K 2010. Beyond the game: Perceptions and practices of corporate social responsibility in the professional sport industry. Journal of Business Ethics 91:433.

Spencer, H 1864. Principles of biology. London: William \& Norgate.

Sundgot-Borgen, J, Meyer, N, Lohman, T, Ackland, T, Maughan, R, Stewart, A \& Müller, W 2013. How to minimise the health risks to athletes who compete in weight-sensitive sports. Review and position statement on behalf of the Ad Hoc Research Working Group on body composition, health and performance, under the auspices of the IOC Medical Commission. British Journal of Sports Medicine 47.16:1012-1022.

United States Anti-Doping Association 2012.

Available online: http://cyclinginvestigation.usada.org/. Accessed $11^{\text {th }}$ Oct 2012.

United Nations Educational, Scientific and Cultural Organisation 2005. International convention against doping in sport. Available online at: http://unesdoc.unesco.org/images/0014/001425/142594m.pdf\#page=2 (accessed on $28^{\text {th }}$ April 2014).

United Nations Educational, Scientific and Cultural Organisation 2006. Sports, winning at any cost? The UNESCO Courier September 2006. Available at: http://unesdoc.unesco.org/images/0019/001915/191579e.pdf (accessed $16^{\text {th }}$ July 2013).

Waddington, I \& Smith, A 2009. An introduction to drugs in sport: Addicted to winning? New York : Routledge.

Wann, D, Melnick, M, Russel, G \& Pease, D 2001. Sport fans: The psychology and social impact of spectators. New York: Routledge.

World Anti-Doping Agency 2009. Code.

Available at:

http://www.wada_ama.org/Documents/World_Anti_Doping_Program/WA

DP-The-Code/WADA_Anti-Doping_CODE_2009_EN.pdf (accessed $27^{\text {th }}$ April 2014).

World Anti-Doping Agency 2012. IOC role models spread play true message. Available from:

http://www.wada-ama.org/en/media-center/archives/articles/ioc-role- modelsspread-play-true-message/ (accessed June $20^{\text {th }}$ 2014).

World Anti-Doping Agency 2016. WADA statement: Independent investigation confirms Russian state manipulation of the doping control process. July 18 , 2016. Available at:

https://www.wada-ama.org/en/media/news/2016-07/wada-statementindependent-investigation-confirms-russian-state manipulation-of (accessed $20^{\text {th }}$ July 2016). 
World Wrestling Entertainment 2014. Sports-entertainment's greatest good guys. Available at: http://www.wwe.com/classics/sports-entertainment-good-guysphotos (accessed 20 $0^{\text {th }}$ June 2014).

World Wrestling Entertainment 2014. The scariest superstars in sports entertainment history. Available at: http://www.wwe.com/classics/thescariest-superstars-in-sports- entertainment-history-photos (accessed $20^{\text {th }}$ June 2014).

Yesalis, C \& Bahrke, M 2002. History of doping in sport. International sports studies 24.1:42-76. 